\title{
Application of fibre composite grids as reinforcement of foamed PC and GP concrete
}

\author{
Rafat Krzywoń ${ }^{1, *}$, Jacek Hulimka ${ }^{1}$, Agnieszka Jędrzejewska ${ }^{1}$, and Marcin Górski ${ }^{1}$ \\ ${ }^{1}$ Silesian University of Technology, Department of Structural Engineering, Akademicka 5, Gliwice 44-100, Poland
}

\begin{abstract}
Cellular concretes cannot be reinforced as easily as traditional ones. Generally porous materials do not ensure sufficient bond of reinforcement; additionally, due to limited amount of aggregate, interlock between aggregate particles and reinforcement ribs is not satisfactory. The idea of reinforcement presented in the paper incorporates bi-directional composite reinforcing grids placed in tensile zone of the cellular concrete slab where transverse fibres are ensuring anchorage for fibres located in the main direction of stresses. The concept is based on geotechnical applications where grids are commonly used as soil stabilization, but the grids adopted in this solution are much stronger thanks to introduction of high strength fibres as composite reinforcement.
\end{abstract}

\section{Introduction}

Foamed or cellular concrete is generally defined as a type of lightweight concrete in which low density is achieved by increased volume of pores in the microstructure of the material. Air voids are introduced by two main methods: direct introduction of air bubbles having the form of technological foam or by endogenous gas generation achieved by mixing of gas-releasing agents. Foamed concrete could be produced with or without the addition of aggregate; usually lightweight porous aggregates are used to further decrease the density of the product.

Depending on its composition and production technology, foamed concrete can be obtained in a wide range of densities, starting from $<300 \mathrm{~kg} / \mathrm{m}^{3}$ to even up to $1900 \mathrm{~kg} / \mathrm{m}^{3}$. Commonly, the density of foamed concrete is a measure used for its qualification because it influences most of its major properties [1,2].

Density of the foamed concrete is determined by the size and distribution of voids. There are two main methods of aerating:

- - by direct introduction of air bubbles through an organic or inorganic foam agent,

- - by mixing the gas releasing agents such as hydrogen peroxide, fine aluminium or zinc powders with cement paste. They react with water and hydroxide in an alkaline environment releasing bubbles of hydrogen gas.

In both cases bubbles are expanding the cement paste. Pores created this way are classified as gel pores, capillary pores and air voids [3]. The foaming method influences the shape, size and volume fraction of pores. Desirable is closed cell structure, it can be achieved if the density has a level allowing the cement paste to isolate individual bubbles, which is easier to achieve in mechanically foamed concretes.

The most commonly used binder for foamed concrete is an ordinary Portland cement (PC concrete), sometimes in combination with fly ash, sand or lime. Such a strong content of Portland cement makes foamed concrete difficult to name eco-friendly material. An interesting alternative may be in this context porous geopolymer. Such material not only allows to reduce the $\mathrm{CO}_{2}$ emission by $80 \%$ [4] but can be produced by synthetizing of industrial waste materials as power plant fly ashes or mining wastes. What is important, foamed geopolymer keeps the strength parameters comparable to the commercially available cellular concrete blocks [5]. However, they are relatively low - especially critically low tensile strength (under $1 \mathrm{MPa}$ ) and brittle characteristic. These properties can be improved by introduction of dispersed or rebar reinforcement into the structure of the material.

This paper describes promising reinforcing technique based on fibre reinforced polymer grids, shows the results of laboratory tests based on foamed concrete specimens and discusses technical capabilities of adaptation of the presented solution for porous geopolymers (GP concrete).

\section{Reinforcing of cellular materials}

Bond between the reinforcement and the surrounding concrete matrix results from the:

- chemical adhesion of the cement paste and steel,

- mechanical interlock between reinforcing bar and concrete.

Chemical adhesion usually is ignored because of its relatively small magnitude, especially in porous materials where the contact surface is limited by the

\footnotetext{
Corresponding author: rafal.krzywon@polsl.pl
} 
voids. For the same reason slip friction is much smaller, because transverse pressure caused by confining concrete matrix can be transferred only at contact points. In this situation crucial is the reinforcement geometry. Interlock between steel ribs and concrete is highly dependent on the concrete strength (density of foamed concrete), bar diameter and ribs geometry. Tests performed by Villers [6] have shown that lightweight foamed concrete of $1200 \mathrm{~kg} / \mathrm{m}^{3}$ density ensures more than eight time lower bond strength than normal concrete based on similar mixture receipt. Poor bond behaviour of cellular concrete is associated with low fracture and stiffness causing premature crushing of concrete by steel ribs.

The authors of this paper proposed yet another concept of reinforcing technique. This idea involves a bidirectional high strength fibre mesh where fibres along main direction act as main reinforcement while transverse fibres serves as an anchorage. The preliminary results obtained at the laboratory tests of 9 slabs [7] showed great potential of this concept: there was a significant increase in capacity and less brittle failure mode. The following paper presents development of these studies with a further 14 models.

\section{Experimental program}

\subsection{Test set-up}

The research program covered 5 reference pure foamed concrete slabs, 9 slabs reinforced with basalt fibre grid and 9 with carbon fibre grid. All tested specimens where made of the same concrete mixture. Applied receipt included Portland cement, a small amount of gravel, water, technical foam, dispersed fibre additive and superplasticizer. Volume weight of ready concrete designed at $800 \mathrm{~kg} / \mathrm{m}^{3}$ was individually controlled for each tested member. Concrete curing was performed in natural conditions, at temperature near $10^{\circ} \mathrm{C}$. In the initial phase members were covered with styrofoam boards to reduce the loss of temperature and water.

Figure 1 shows the test set-up scheme. Slab-type elements were designed with section dimensions $120 \times$ $350 \mathrm{~mm}$, total length about $700 \mathrm{~mm}$ and span length 600 $\mathrm{mm}$. Such configuration provides span-to-depth ratio equal to 5 which should effectively reduce the impact of shear on the final results.

\subsection{Properties of materials}

As it is difficult to ensure proper bond of reinforcement due to brittleness of foamed concrete, specimens were reinforced with composite grid wherein the perpendicular strands provide anchorage. Two types of grids were used:

- grid based on relatively cheap basalt fibre BSC220.220.260.100 delivered by INCOTELOGY $\mathrm{GmbH}$ [8],

- more expensive, but also stronger carbon fibre grid C-GRID ${ }^{\circledR C} 50-2.36 \times 2.36$ delivered by $\mathrm{B} \& \mathrm{R}$ building Materials Belgium and produced by Chomarat France [9].

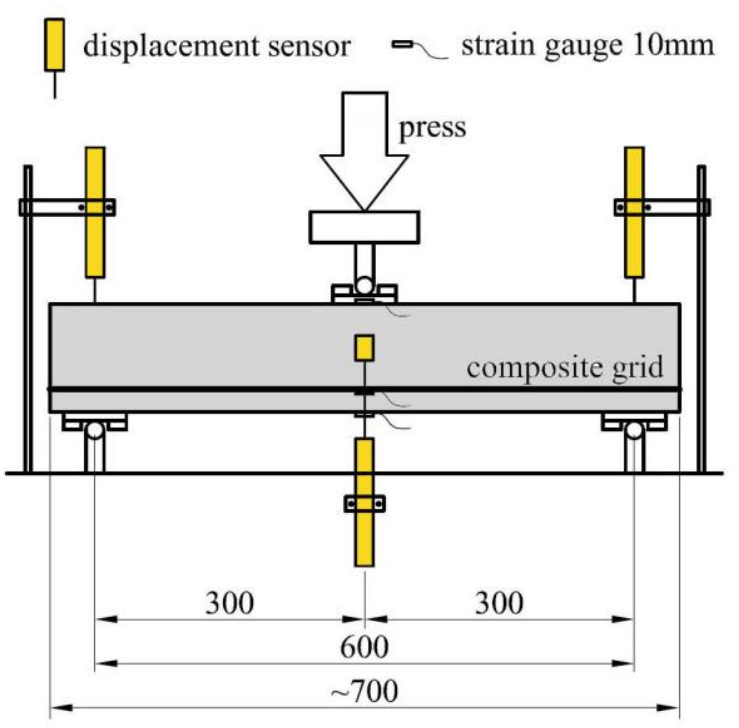

Fig. 1. Test set-up.

To determine the properties of the foam concrete on the day of the test, cube and cylinder samples were tested after 54 days of curing simultaneously with the main experiment. According to the standard PN EN 12390$3: 2009$ [10], compressive strength, $\mathrm{f}_{\mathrm{c} \text {, cube, was evaluated }}$ on six single cubes with side dimensions of $120 \mathrm{~mm}$, while compressive cylindrical strength, $f_{c}$, and secant modulus of elasticity, $E_{c}$, were estimated by testing six cylinders with a diameter of $150 \mathrm{~mm}$ and height of 300 $\mathrm{mm}$. The mean results are shown in Table 1.

The grid properties were assumed on the basis of the values declared by the producers. Table 2 shows the comparison of selected features of the applied meshes.

Table 1. Hardened foam concrete strength properties.

\begin{tabular}{|c|c|c|c|}
\hline $\begin{array}{c}\text { Age of test } \\
{[\text { days }]}\end{array}$ & $\begin{array}{c}\mathbf{f}_{\mathbf{c}} \\
{[\mathrm{MPa}]}\end{array}$ & $\begin{array}{c}\mathbf{f}_{\mathbf{c}, \text { cube }} \\
{[\mathrm{MPa}]}\end{array}$ & $\begin{array}{c}\mathbf{E}_{\mathbf{c}} \\
{[\mathrm{GPa}]}\end{array}$ \\
\hline 54 & 1.68 & 1.84 & 1.65 \\
\hline
\end{tabular}

Table 2. Composite grid features.

\begin{tabular}{|c|c|c|}
\hline Type o fibres & $\begin{array}{c}\text { BSC220.220.26 } \\
0.100\end{array}$ & $\begin{array}{c}\text { C-GRID®C50- } \\
2.36 \times 2.36\end{array}$ \\
\hline Net geometry & $25 \times 25 \mathrm{~mm}$ & $60 \times 60 \mathrm{~mm}$ \\
\hline Break load $[\mathrm{kN} / \mathrm{m}]$ & $>50$ & $>54.17$ \\
\hline $\begin{array}{c}\text { Elongation at break } \\
{[\%]}\end{array}$ & $2.5 \pm 1$ & 0.99 \\
\hline $\begin{array}{c}\text { Tensile modulus of } \\
\text { elasticity }[\mathrm{MPa}]\end{array}$ & $86 \div 94$ & 234.5 \\
\hline
\end{tabular}




\subsection{Test procedure}

Laboratory tests were executed in three-point bending test (Fig. 1). Force was applied using a hydraulic press, monotonically with loading speed of $0.05 \mathrm{kN} / \mathrm{s}$. To determine deflections, test stand was equipped with linear displacement transducers at three points along the slab's length (at supports and in the middle of the span). Electrical strain gauges were fixed to the reinforcement and on upper and bottom surface of each slab. Due to the homogeneous structure of foam concrete, relatively short gauges were used with a base length of $10 \mathrm{~mm}$.

Additionally, the test was recorded using high resolution camera to allow optical analysis of strains and displacements, especially crack propagation and width.

\section{Test results}

All tested models were casted of one mix, however, the foamed concrete is sensitive to the way and order of laying in the formwork, therefore during the test the density of each of the tested slab was measured individually and given in Table 3. Average density of used concrete was equal to $765 \mathrm{~kg} / \mathrm{m}^{3}$ and standard deviation $24 \mathrm{~kg} / \mathrm{m}^{3}$.

\subsection{Failure load}

The most veritable factor to evaluate effectiveness of the proposed reinforcing method is the increase in loadbearing capacity of tested slabs. Achieved results in this regard should be considered as very promising. They are summarized in Table 3. As expected, the highest load capacity was recorded for samples reinforced with carbon fibre grid. The highest failure force was $11.79 \mathrm{kN}$ in this case, while mean bearing capacity was $9.20 \mathrm{kN}$. The efficiency of the basalt net was slightly lower - the mean failure force reached $8.74 \mathrm{kN}$. In essence, in both cases, the increase in load capacity compared to the unreinforced models was over six times.

In any of the models tested, reinforcing grids did not break during the failure. Differences in bearing capacities of basalt-reinforced (BC) specimens and carbon-reinforced (CC) specimens can be explained by higher modulus of elasticity of carbon fibres. As a result of smaller rotation of cross-section, the strains and consequently also the stresses were lower delaying the delamination of reinforcement.

Analysing failure modes an interesting observation can be made on the basis of comparison of failure images of unreinforced and reinforced slabs (Fig. 2 and 3). Specimens without reinforcement failed in a conventional manner, after cracking in the crosssection of the largest bending moment. Initial mechanism of failure of the slabs reinforced with basalt and carbon grids was similar - vertical crack occurred under the loading force (Fig. 3a). Finally, all reinforced models failed due to inclined shear crack with delamination and slippage along the surface of the reinforcing grid (Fig 3b, 3c). This confirms that transverse fibres provide effective anchorage, but at extreme load they act like a knife cutting sample through the plane of the grid (Fig. 4).

Table 3. Test results of FC reinforced slabs [11].

\begin{tabular}{|c|c|c|c|c|}
\hline \multicolumn{2}{|c|}{ Model } & $\begin{array}{l}\text { Density } \\
{\left[\mathrm{kg} / \mathrm{m}^{3}\right]}\end{array}$ & $\begin{array}{c}\text { Failure } \\
\text { force }\end{array}$ & $\begin{array}{l}\text { Deflection } \\
\text { at failure }\end{array}$ \\
\hline $\mathrm{FC} 1$ & \multirow{6}{*}{ 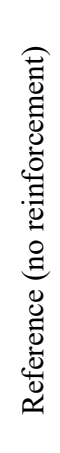 } & 778 & 0.95 & 0.98 \\
\hline $\mathrm{FC} 2$ & & 793 & 1.20 & 1.13 \\
\hline FC3 & & 778 & 1.27 & 1.39 \\
\hline FC4 & & 752 & 1.68 & 0.58 \\
\hline FC5 & & 752 & 1.46 & 0.41 \\
\hline mean & & 771 & 1.31 & 0.90 \\
\hline $\mathrm{BC} 1$ & \multirow{10}{*}{ 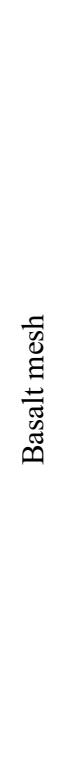 } & 763 & 9.20 & 10.25 \\
\hline $\mathrm{BC} 2$ & & 798 & 7.93 & 6.04 \\
\hline $\mathrm{BC} 3$ & & 809 & 9.24 & 8.31 \\
\hline $\mathrm{BC} 4$ & & 779 & 8.42 & 11.44 \\
\hline BC5 & & 743 & 7.42 & 7.84 \\
\hline BC6 & & 787 & 9.36 & 8.11 \\
\hline $\mathrm{BC} 7$ & & 769 & 8.93 & 9.32 \\
\hline BC8 & & 729 & 8.08 & 16.1 \\
\hline BC9 & & 781 & 10.16 & 12.19 \\
\hline mean & & 773 & 8.75 & 9.96 \\
\hline $\mathrm{CC} 1$ & \multirow{10}{*}{ 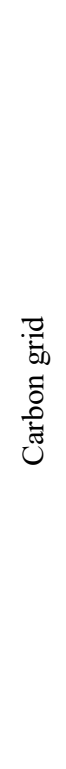 } & 767 & 11.79 & 7.46 \\
\hline $\mathrm{CC} 2$ & & 774 & 10.75 & 7.91 \\
\hline $\mathrm{CC} 3$ & & 744 & 9.96 & 6.57 \\
\hline $\mathrm{CC} 4$ & & 742 & 9.94 & 6.95 \\
\hline CC5 & & 772 & 6.61 & 5.41 \\
\hline CC6 & & 776 & 8.37 & 8.38 \\
\hline $\mathrm{CC} 7$ & & 768 & 9.77 & 3.81 \\
\hline CC8 & & 724 & 7.99 & 11.26 \\
\hline CC9 & & 731 & 7.58 & 6.19 \\
\hline mean & & 755 & 9.20 & 7.10 \\
\hline
\end{tabular}


One of the models tested (BC_7) broke due to the shrinkage through the whole depth. Reinforcement remained the only element that joined two separated parts. In spite of this, achieved bearing capacity does not deviate from other samples. This result proves that although the reinforcement does not completely prevent formation of shrinkage strains, it effectively minimizes the consequences of this phenomenon. It should be also emphasized that the number of shrinkage cracks observed on reinforced samples was significantly lower in comparison to the reference models without reinforcement.

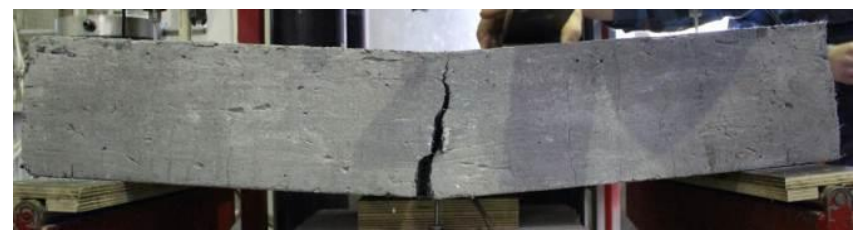

Fig. 2. Typical failure mode of the reference unreinforced specimens.

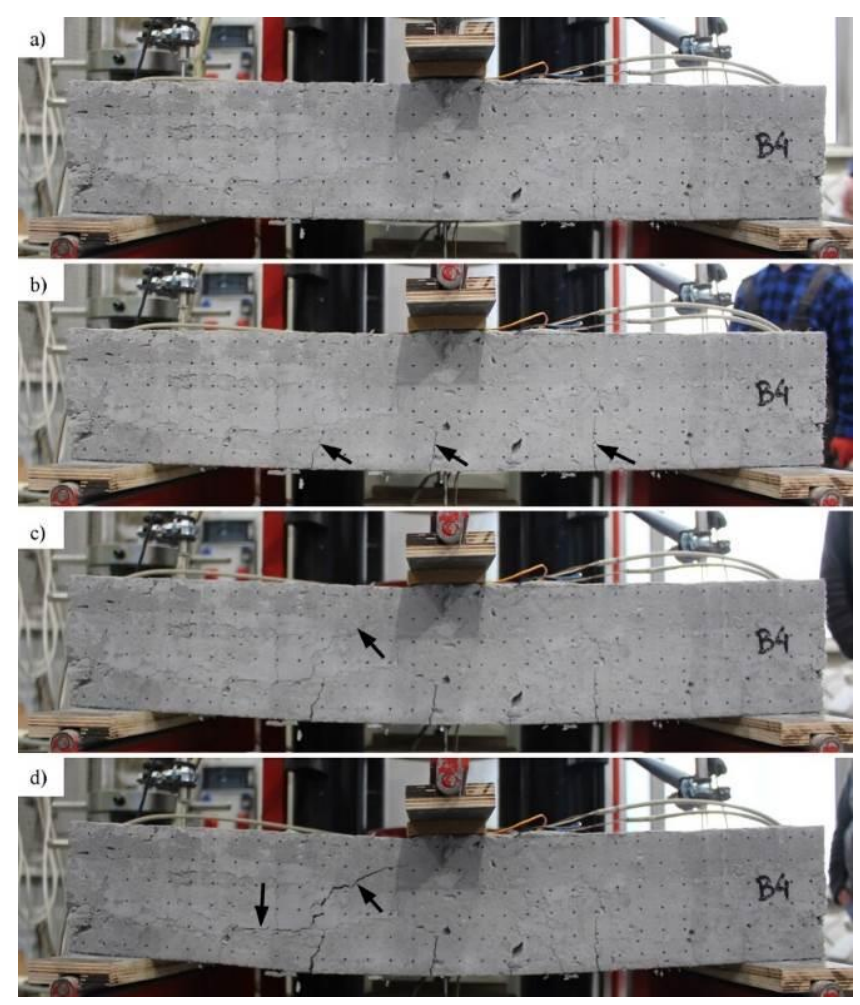

Fig. 3. Failure process of the reinforced slab: a) initiation of vertical cracking; b) development of vertical cracking; c) appearance of inclined crack; d) failure with delamination initiated by the inclined crack.

\subsection{Deformations}

Figure 5 shows the comparison of the mid-span deflection curves for selected tested specimens. The effect of more than twice higher value of the elastic modulus of carbon fibres can be observed as differences in deflection. The scale of difference shows much greater impact of the reinforcement parameters on the deformability of specimens made of foam concrete than it is recognized for models made of ordinary concrete.

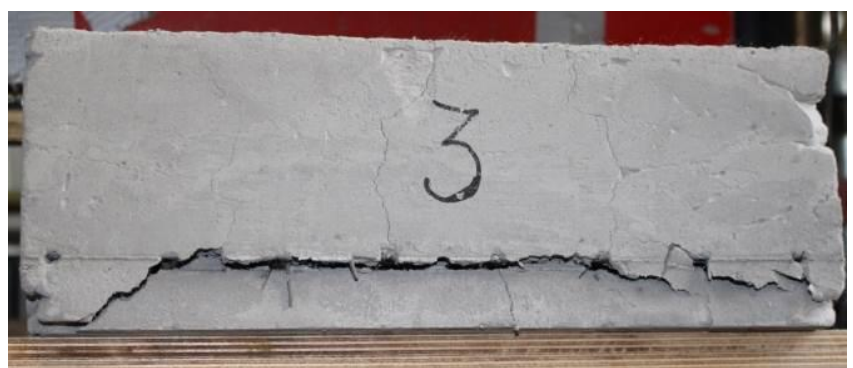

Fig. 4. Shear failure and delamination along the composite grid.

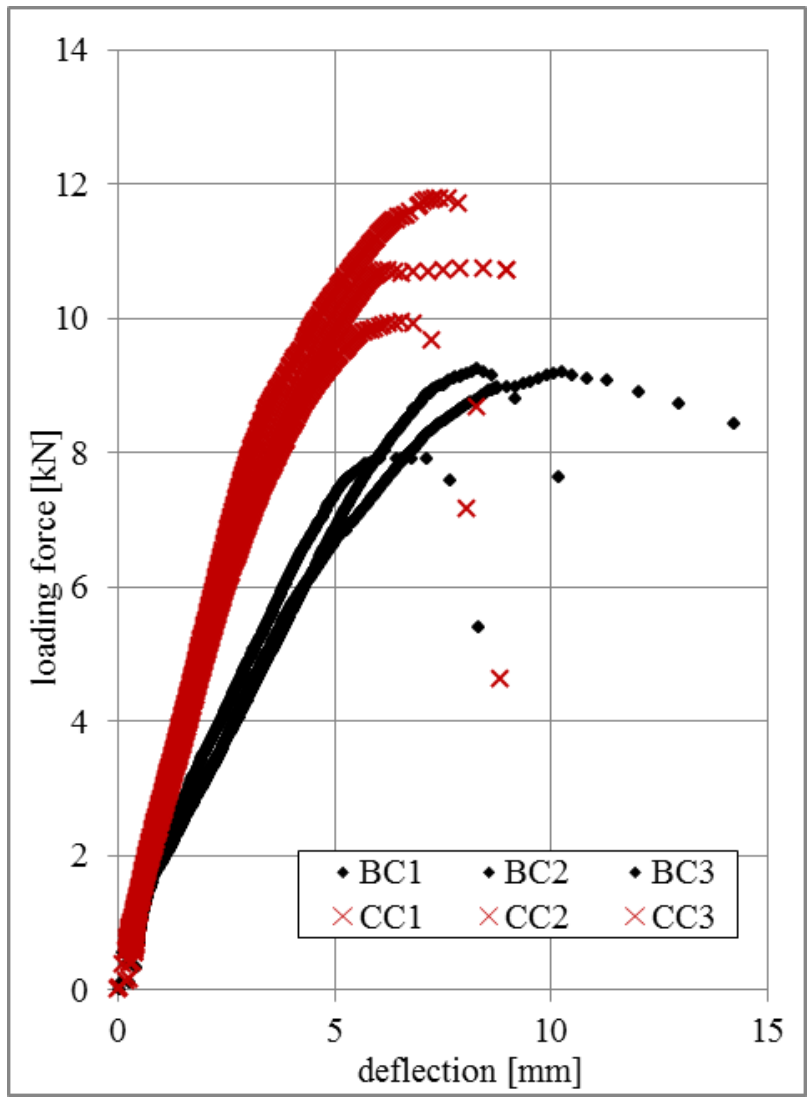

Fig. 5. Deflection curves of selected FC reinforced slabs [7].

\section{Technical ability to use composite grids as reinforcement of porous geopolymers}

Reinforcement of ordinary concrete with FRP bars is currently one of the most intensively developed matters related to concrete. Also the issue of geopolymer reinforcement is finding an increasing interest among researchers, however, it mainly concerns traditional steel reinforcement $[12,13]$, and examples of research on the reinforcement of FRP are scarce [14]. Nevertheless, the experience and knowledge of the properties of the materials mentioned allow for prediction of the working conditions of a reinforced geopolymer. Such discussion will be carried out in this chapter. 


\subsection{Chemical compatibility}

Composite reinforcement is commonly used today in concrete structures but the negative impact of the alkaline environment is not known [15]. The exceptions are some types of glass fibre composites that may need to be protected using appropriate vinyl ester resins [16]. The influence of the alkaline environment is enhanced by the high temperature, which is indicated in the curing of geopolymers.

The carbonation process is not a threat to FRP composites, also the presence of chlorides contained in the concrete has no noticeable effect [16]. Similar resistance can be expected within the geopolymer structure. Composite bar is also resistant to corrosion caused by water migration in porous material. However, the properties of polymer resins can be degraded by the water molecules taking on the role of resin plasticizers, disrupting Van-der-Waals bonds in polymer chains [17]. The result of such reactions is the decrease in strength, modulus of elasticity and durability of the resin matrix.

\subsection{Thermal issues}

Most of fibre composites intended for reinforcement of concrete structures is based on epoxy binders. Because of that they are not resistant to high temperatures. Commonly the temperatures up to $60^{\circ} \mathrm{C}$ are considered safe for epoxies. In practice, this excludes the use of geopolymers subjected to high temperature processing, however, most of them should be classified as porous ceramics rather than concrete and they are applicable as replacement of small size specimens not requiring reinforcement (clay bricks and blocks).

Low temperature processing allows to achieve slightly lower strength properties, geopolymer foams are relatively less homogenous, but products are more energy efficient and cost effective [18]. Ambient temperature is also more friendly for FRP composites. Two methods of foaming may be applied in this case.

- chemical foaming by addition of Al powder [19], $\mathrm{H}_{2} \mathrm{O}_{2}$ [20] or silica fume [21],

- mechanical pre-foaming [22].

Although most of the cited methods assume about 24 hours of heat-curing but undergone in acceptable temperature of $60^{\circ} \mathrm{C}$.

An additional problem of chemical foaming methods could be the exothermic nature of the reaction. It may cause an additional increase in temperature, dangerous for the durability of some types of fibres (eg glass).

\subsection{Reinforcement stabilisation}

Composite grids are more flexible than ordinary rebar reinforcement, therefore stabilizing their position is a relatively difficult task, especially for elements such as slab. Addition of chemical reactant into a geopolymer mixture starts volumetric changes resulting from the formation of pores. In such a situation it should be expected that pressure induced by the geopolymer mixture will move the grid, despite the openings in its structure. Slabs are usually poured in horizontal position. In this situation, the reinforcement will be raised, which will reduce the lever arm and thus the flexural load capacity of the cross-section.

More stable mixture can be obtained by applying mechanical pre-foaming technique, however, this is a relatively new method and only limited information is available regarding the composition and properties of such a material [18]. For density of $850-950 \mathrm{~kg} / \mathrm{m}^{3}$ Zhang [22] reported a compressive strength of 4-9 $\mathrm{MPa}$ depending on the alkali activator. Abdullah [23] for higher density $\left(1650-1667 \mathrm{~kg} / \mathrm{m}^{3}\right)$ has got very promising 28 day strength of $18.2 \mathrm{MPa}$, equal for heatcured and room temperature cured samples.

\section{Summary and conclusions}

Performed tests have proven that internal composite reinforcement has beneficial effect on foam concrete specimens under flexure.

Transverse grid strand created expected, effective anchorage for fibres in main direction. Unfortunately, in the critical phase it contributed to the cause of destruction, however, the global impact of reinforcement should be assessed positively. Mean failure load of the elements reinforced with high strength fibre composite grid is more than 6 times higher than in the elements without such reinforcement.

Due to dimensional stability and thermal effects as the most useful for the proposed reinforcement technique can be considered lightweight geopolymer processed by the mechanical pre-foaming.

Paper showed studies of specimens made of relatively weak type of foam concrete. Jones and McCarthy evaluate the density suitable for engineering applications at $1400 \mathrm{~kg} / \mathrm{m}^{3}$ [24]. The study will be continued with the use of higher density foam concretes and foam geopolymers, also with other types of reinforcing grids, such as glass and cheap PP geogrids.

Authors want to acknowledge AKCES BK Sp. z o.o., Czechowice Dziedzice, Poland for the technical assistance in production of samples.

\section{References}

1. M. Kadela, M. Kozłowski, Advances in Materials Science and Engineering 2018 (2018)

2. M. Kozłowski, M. Kadela, A. Kukielka, Procedia Engineering 108, 349-354 (2018)

3. M. Visagie, E.P. Kearsely, Concrete Beton 101, 814 (2002)

4. P. Duxson, J.L. Provis, G.C. Lukey, J.S. Van Deventer, Cement Concrete Research 37(12) 1590 1597 (2007)

5. Z. Abdollahnejad, F. Pacheco-Torgal, J. B. de Aguiar, Advanced Materials Research 1129, 565572 (2015)

6. J.P. de Villers, G. van Zijl, A.S. van Royen, Structural Concrete 18, 496-506 (2017) 
7. J. Hulimka, R. Krzywoń, A. Jędrzejewska, Procedia Engineering 193, 337-344 (2017)

8. Technical Data Sheet BSC220.220.260.100 FGMW0019, Incotelogy GmbH, Germany (2014)

9. Technical Data Sheet C-Grid reinforced C502.36x2.36, B\&R Bulding Materials, Arendonk, Belgium (2010)

10. PN EN 12390-3:2009 Testing hardened concrete. Compressive strength of test specimens

11. R. Krzywoń, J. Hulimka, A. Jędrzejewska, Journal of Civil Engineering, Environment and Architecture 34(64) 341-350 (2017)

12. P.K. Sarker, Advances in Science and Technology 69,143-51 (2010)

13. J.K. Dattatreya, N.P. Rajamane, D. Sabitha, P.S. Ambily, M.C. Nataraja, International Journal of Civil and Structural Engineering 2, 138-59 (2011)

14. G.B. Maranan, A.C. Manalo, W. Karunasena, B. Benmokrane, P. Mendis, D. Lutze, Composites Australia and CRC-ACS Conference - Materials for a Lighter and Smarter World, Gold Coast Australia (2015)

15. C.E. Bakis, Advances in FRP Composites in Civil Engineering, 33-36 (2011)

16. H. Wang, A. Belarbi, Construction and Building Materials 44, 541-550 (2013)

17. B. Benmokrane, M.H. Mohamed, Concrete International, 36 (2), 40-45 (2014)

18. Z. Zhang, J.L. Provis, A. reid, H. Wang, Construction and Building Materials 59, 113-127 (2014)

19. R.A. Aguilar, O.B. Diaz, J. Garcia, Construction and Building Materials 24, 1166-1175 (2010)

20. J. Feng, R. Zhang, L. Gong, Y. Li, W. Cao, X.Cheng, Materials and Design 65, 529-533 (2015)

21. E. Prud'homme, P. Michaud, Journal of the European Ceramic Society 30(7), 1641-1648 (2010)

22. Z. Zhang, H. Wang, A. Reid, T. Aravinthan, Incorporating sustainable practice in mechanics of structures and materials (CRC Press, Taylor \$ Francis Group, Melbourne, Australia 2010)

23. M. Al Bakri Abdullah, K. Hussin, M. Bnhussain, K. Ismail, Z. Yahna, R. Razak, International Journal of Molecular Sciences 13(6), 7186-7198 (2012)

24. M.R. Jones, A. McCarthy, Magazine of Concrete Research 57(1), 21-31 (2005) 